Baydaa A. Othman Al-Rawi BDS, MSc (Assist Lect)

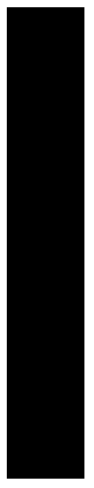

\section{Evaluation of Intruded Primary In- cisors: One Year Follow Up Study}

Dept of Pedod, Orthod and Prev Dentistry

College of Dentistry, University of Mosul

\begin{abstract}
Aims: To evaluate the epidemiological aspects related to tooth intrusion during the primary dentition through examination and monitoring patients, as well as to find the correlation between the severity of intrusion and the consequences to the primary tooth itself that could occur. Materials and methods : This is a prospective observational study. Patients seen in the Pedodontics Clinic of College of Dentistry, University of Mosul who have suffered intrusive injuries of primary incisors. Patients included in this study should brought to Pedodontics Clinic with the first 24 hours from the occurrence of the accident. The children were assumed to be healthy and the intrusive teeth should not have previously received any pulp therapy or conservative restoration. Patients must have an initial X-ray; must have at least 12 months of monitoring; and their records must be adequately filled in. Results: The records of 39 patients with intrusion were analyzed and according to the inclusion criteria, 32 patients took part in the present study. The patients were between 2 and 4 years of age. There was slightly more girls (15, $53.6 \%$ ) with dental trauma than boys $(13,46.4 \%)$, but not reach a significant level $(p>0.05)$. All the intrusive teeth were upper central incisors. Concerning the severity of intrusion; mild intrusion was 7 (21.9\%) teeth, moderate intrusion was 20 (62.5\%), while severe one was $5(15.6 \%)$ teeth. Conclusions: In aiming to minimize developmental disturbances in the permanent dentition, the most effective methods are firstly to obtain an exact diagnosis, then to provide correct first -aid treatment and finally to perform regular follow ups.

Key words: Intrusion, incisors.
\end{abstract}

Al-Rawi BA. Evaluation of Intruded Primary Incisors: One Year Follow Up Study. Al-Rafidain Dent J. 2009; 9(2): 254-258.

Received: $18 / 5 / 2008$

Sent to Referees: $18 / 5 / 2008$

Accepted for Publication: 21/8/2008

\section{INTRODUCTION}

From birth, a child is exposed to traumatic episodes, which depend on the energy of the impact, can result in injuries which may range in severity from minor problems to life - threatening cases ${ }^{(1)}$.Trauma to the oral region occurs frequently and comprise 5\% of all injuries for people who seek treatment. ${ }^{(2)}$.

Intrusive dislocation consists of the dislocation of the tooth into the interior of the alveolar bone and may be accompanied by a fragmentation or fracture of the alveolar cavity. This type of trauma is most common during the phase of primary dentition when the patient is between 1 and 3 years of age, a period when the crowns of the permanent successors are being formed and the alveolar bone is more resilient ${ }^{(3)}$.
The management of traumatic injuries to primary teeth differs from that used for permanent. It is important to keep in mind that there is relationship between the apex of the root of the injured primary tooth and the underlying permanent tooth germ. Thus, treatment of the traumatized primary tooth is aimed at minimizing damage to this tooth and the factors that might cause alteration in the germ of the permanent tooth, with successful treatment being dependent on the age of the child at the time of trauma, type and severity of the injury, and the period between dental trauma and care ${ }^{(4,5)}$.

The aim of this study is to evaluate the epidemiological aspects related to tooth intrusion during primary dentition through examination and monitoring of patients, as well as to find the correlation between the 
severity of intrusion and the consequences to the primary tooth itself that could occur.

\section{MATERIALS AND METHODS}

This a prospective observational study. Patients involved in this study were those attending the Pedodontic Clinic of College of Dentistry, University of Mosul who suffered intrusive injuries of primary incisors. Patients included in this study should be brought within the first 24 hours from the occurrence of the accident.

The children were assumed to be healthy and the intrusive teeth should not conservative restoration. Patients must have an initial X-ray, have at least 12 months of monitoring and their records must be adequately filled in. From the diagnosis onwards the patients receive standard treatment and are monitored for pre-established periods $^{(6)}$.

The records of the patients being observed were analyzed for the following aspects: age, gender, cause of accident, immediate treatment carried out, extraction or waiting for spontaneous re-eruption.

The important aspect to be evaluated is the direction of impact on the intruding teeth, as this information may lead to the possible injury to the germs of the permanent teeth, if the apex of the root was displaced toward the labial bone plate, the tooth is left for spontaneous re - eruption. If the apex is displaced to the lingual dislocation, which is the location where the permanent successor develops, the tooth should be extracted.

There was a minimum of 15 days for teeth to be extracted during the clinical control phase. Also, it was important to assess its association with other types of trauma, the number and type of teeth involved, the process of re-eruption as following; total re-eruption without consequences to the primary tooth itself, total re-eruption with some consequences, partial re-eruption and no re-eruption.

The vitality of dental pulp is evaluated throughout the monitoring process by clinical observations (alterations in color, the existence of fistula) and radiological observations (the existence of internal and / or external root resorption, periapical pathol- ogy and root canal obliteration). Periodontal condition evaluated through clinical observation and mobility test ${ }^{(4,7)}$. The severity of intrusion classified to: mild (less than $3 \mathrm{~mm}$ intruded), moderate (half of the crown intruded), and sever (complete crown intruded) ${ }^{(8)}$

Patients were reviewed at 1 week, 2 weeks, 3 months, 6 months, 9 months and 12 months after injury. In every follow-up visit, the patient received a clinical and radiographical assessments to described any pulpal and periodontal pathology ${ }^{(8)}$.

Data were analyzed using numbers and percentages. Z-test between two proportions was used to find if there is any gender variation, while chi -square $\left(x^{2}\right)$ test was used to find if there is significant relationship between the process of re-eruption and severity of intrusion. The level of significant set at $p \leq 0.00$.

\section{RESULTS}

The records of 39 patients with intrusion were analyzed and according to the inclusion criteria, 32 patients took part in the present study. Four patients excluded from the study due to failure to follow up visits. Only two cases with severe intrusion were extracted during the clinical control phase (1 week from the occurrence of incidence) because in addition to the intrusion there was a significant lateral dislocation with great mobility.

A total of 30 teeth were the final number of teeth included in the study. The patients were between 2 and 4 years of age. The average age of the patients was 3 years. There was slightly more girls (15, $53.6 \%)$ with dental trauma than boys (13, $46.4 \%)$ but did not reach a significant level ( $p>0.05)$ (Table 1).

In relation to the causes of intrusive injuries, the following results were observed: a fall from their own height while walking or running $(16,57.1 \%)$; while playing with tricycle $(5,17.9 \%)$; impact against a hard object $(5,17.9 \%)$; in some cases the responsible party did not know how the accident had happened $(2,7.1 \%)$ (Table 1). 
Table (1): Numbers and percentages of patients' distribution according to gender and the causes of traumatic injuries.

\begin{tabular}{|c|c|c|c|c|c|}
\hline & $\begin{array}{c}\text { Fall while } \\
\text { walking or } \\
\text { running } \\
\text { No. (\%) }\end{array}$ & $\begin{array}{c}\text { Playing with } \\
\text { tricycle } \\
\text { No. (\%) }\end{array}$ & $\begin{array}{c}\text { Impact } \\
\text { against a } \\
\text { hard object } \\
\text { No. (\%) }\end{array}$ & $\begin{array}{c}\text { Unknown } \\
\text { No. (\%) }\end{array}$ & $\begin{array}{c}\text { Total } \\
\text { No. (\%) }\end{array}$ \\
\hline Female & 8 & 2 & 3 & 2 & $15(53.6)$ \\
\hline Male & 8 & 3 & 2 & 0 & $13(46.4)$ \\
\hline Total & $16(57.1)$ & $5(17.9)$ & $5(17.9)$ & $2(7.1)$ & $28(100)$ \\
\hline
\end{tabular}

All the intrusive teeth were upper central incisors. Concerning the severity of intrusion; mild intrusion was $7(23.3 \%)$ teeth, moderate intrusion was $20(66.7 \%)$, while severe one was $3(10.0 \%)$ teeth (Table 2).As to the process of spontaneous re -eruption it can be observed that in $(6$, $20 \%$ ) of the teeth there was total spontaneous re-eruption without any type of consequences. In $(18,60 \%)$ of cases, there was total re-eruption, however, this was accompanied by consequences such as discoloration, necrosis of the pulp, periapical pathology with existence of fistula. There was no existence of root resorption or root canal obliteration. There was partial re-eruption in $(4,13.3 \%)$ of cases and no eruption in $(2,6.7 \%)$ of cases (Table
2).

Also Table (2) revealed that there was significant relationship $(p \leq 0.05)$ between the severity of intrusion and the process of re-eruption. Most mild intruded cases were total re-eruptions without consequences, while most of moderate intruded cases were total re-erupted with some consequences, and most of sever intrude cases were not re-erupted.

According to the management routine, all teeth with consequences such as discoloration, necrosis of the pulp and periapical pathology with or without existence of fistula were treated endodontically, while the non re -erupted teeth were extracted.

Table (2) Numbers and percentages of intruded teeth's distribution according to the severity of intrusion and the processes of re-eruption.

\begin{tabular}{lccccc}
\hline & $\begin{array}{c}\text { Total } \\
\text { re-eruption } \\
\text { without conse- } \\
\text { quences } \\
\text { No. }\end{array}$ & $\begin{array}{c}\text { Total } \\
\text { re-eruption } \\
\text { with some } \\
\text { consequences } \\
\text { No. }\end{array}$ & $\begin{array}{c}\text { Partial } \\
\text { re- } \\
\text { eruption } \\
\text { No. }\end{array}$ & $\begin{array}{c}\text { No } \\
\text { re-eruption } \\
\text { No. }\end{array}$ & $\begin{array}{c}\text { Total } \\
\text { No. }\end{array}$ \\
\hline Mild & 5 & 2 & 0 & 0 & $7(23.3 \%)$ \\
Moderate & 1 & 16 & 3 & 0 & $20(66.7 \%)$ \\
Severe & 0 & 0 & 1 & 2 & $3(10.0 \%)$ \\
Total & $6(20 \%)$ & $18(60 \%)$ & $4(13.3 \%)$ & $2(6.7 \%)$ & $30(100 \%)$ \\
\hline
\end{tabular}

Chi-square $\left(x^{2}\right)$ test $=19.850 p 0.001$.

\section{DISCUSSION}

Dental trauma is frequent in infancy, Andreasen et al., ${ }^{(2)}$ stated that these injuries occur mainly during early infancy (be- tween 2 and 3 years of age). This study has a similar age range ( $2-4$ years), with a non significant greater number of girls suffering injuries than boys which was 
agreed with other researches ${ }^{(6,9,10)}$, while disagreed with others ${ }^{(11,12)}$ who found that boys have significantly more injuries than girls. These differences related to the population variations.

The main causes of these accidents were: falls from their own height while walking or running or playing with tricycle or impact against a hard object and in some cases the responsible party did not know how the accident had happened. From our results and the data obtained from other researchers it can be observed that in most cases both the age range and the reason for the trauma are related to the period when children are learning to walk $(2,6,13)$. Under these conditions, preventive care is difficult as the child has few defensive reflexes during this developmental stage.

Concerning the type of teeth intrused, the upper central incisors are involved, because of their anatomical location, which leaves them more exposed and thus vulnerable to injury and these findings are similar to those reported by other authors $(6,13-15)$

According to many researches ${ }^{(16,17)}$, they observed that the amount of time spent by parents between the incidence and seeking dental assistance greatly was increase the chances of successful treatment and minimize the occurrence of sequelae. For these reasons, only those patients who brought to Pedodontics Clinic within the first 24 hours from the occurrence of the incident were included in this study.

In most dental trauma studies ${ }^{(4,7,16,17)}$, he outcome of healing has been related to the severity of injury sustained, which agreed with the findings of this study were the re-eruption process significantly associated with the severity of intrusion $(p \leq$ 0.05 ) and the most mild intruded cases were total re-eruptions without consequences, as well as most of moderate intruded cases were total re-erupted with some consequences, while most of sever intrude cases were not re -erupted may be due to ankylosis.

\section{CONCLUSIONS}

According to the results it can be con- cluded that children are commonly affected by intrusion luxation injuries, especially in their early years. There was a non significant greater number of girls suffering injuries than boys and the main cause of these accidents was falls from their own height while walking or running. The outcome of healing has been related to the severity of injury sustained and the most common consequences of intrusions were discoloration, necrosis of the pulp and periapical pathology with or without existence of fistula. There was no existence of root resorption or root canal obliteration. In aiming to minimize developmental disturbances in the permanent dentition, the most effective methods are firstly to obtain an exact diagnosis, then to provide correct first -aid treatment and lastly to perform regular follow ups.

\section{REFERENCES}

1. Gabris K, Tarjan I, Rozsa N. Dental trauma in children presenting for treatment at the Department of Dentistry for Children and Orthodontics, Budapest, 1985 99. Dent Traumatol. 2001; 17: 103 - 108.

2. Andreasen JO, Andreasen FM, Andersson L. Textbook and color atlas of traumatic injuries to the teeth. $4^{\text {th }}$ ed. Oxford, Blackwell Munksgaard. 2007.

3. Bassat BY. Effect of trauma to the primary incisor on root development of their permanent successors. Pediatr Dent. 1986; 8: $289-293$.

4. Flores MT, Malmgren B, Andersson L, Anderasen JO, Bakland LK, Barnett F, Bourguignon C, DiAngelis A, Hicks L, Sigurdsson A, Trope M, Tsukiboshi M, Von Arx T. Guidelines for the management of traumatic dental injuries. III Primary teeth. Dent Traumatol. 2007; 23: 196 $-202$.

5. Cunha RF, Delbem SCB, Percinoto C, Saito TE. Dentistry for babies: a preventive protocol. J Dent Child. 2000; 67: 89 92.

6. Gondim JO, Moreira Neto JJS. Evaluation of intruded primary incisors. Dent Traumatol. 2005; 21: 131 - 133.

7. Cardoso M, Rocha MJC. Federal University of Santa Catarina follow-up management routine for traumatized primary teeth -Part I. Dent Traumatol. 2004; 20: 307 - 
313.

8. Tsukiboshi M. Treatment planning for traumatized teeth. Quintessence Publishing Company, Inc. 2000.

9. Yagot KH, Nazhat NY, Kuder SA. Traumatic dental injuries in nursery school children from Baghdad, Iraq. Community Dent Oral Epidemiol. 1988; 16: 292 - 293.

10. Altay N, Güngör HC. A retrospective study of dento-alveolar injuries of children in Ankara, Turkey. Dent Traumatol. 2001; 17: $201-204$.

11. Kahabuka FK, Plasschaert A, Van't Hof MA. Prevalence of teeth with untreated dental trauma among nursery and primary school pupils in Dar es Salaam, Tanzania. Dent Traumatol. 2001; 17: 109 - 113.

12. Skaare AB, Jacobsen I. Primary tooth injuries in Norwegian children (1 8years). Dent Traumatol. 2005; 21: 315 319.

13. Rodriguez JG. Traumatic anterior dental injuries in Cuban preschool children. Dent
Traumatol.2007; 23: $241-242$.

14. Caldas AF Jr, Burgos MEA. A retrospective study of traumatic dental injuries in a Brazilian dental trauma clinic. Dent Traumatol. 2001; 17: 250 - 253.

15. Cardoso M, de Carvalho Rocha MJ. Traumatized primary teeth in children assisted at the Federal University of Santa Catarina, Brazil. Dent Traumatol. 2002; 18: $129-133$.

16. Andreasen JO, Andreasen FM, Skeie A, Hjørting-Hansen E, Schwartz O. Effect of treatment delay upon pulp and periodontal healing of traumatic dental injuries-a review article. Dent Traumatol. 2002; 18: $116-128$.

17. Pugliesi DMC, Cunha RF, Delbem ACB, Sundefeld MLMM. Influence of the type of dental trauma on the pulp vitality and the time elapsed until treatment: a study in patients aged $0-3$ years. Dent Traumatol. 2004; 20: $139-142$. 